\title{
The Acquisition of Binomials by Kuwaiti EFL Learners
}

\author{
Abdullah M. Alotaibi ${ }^{1} \&$ Maye A. Alotaibi ${ }^{2}$ \\ ${ }^{1}$ Associate Prof at PAAET \& CBE, Kuwait \\ ${ }^{2}$ English Lecturer at PAAET \& CBS, Kuwait \\ Correspondence: Abdullah M. Alotaibi, P. O. Box 66821, 43759 Bayan, The State of Kuwait. E-mail: \\ alotaibi917@gmail.com or otaiby2013@gmail.com
}

Received: February 2, 2015 Accepted: March 2, 2015 Online Published: May 30, 2015

doi:10.5539/ijel.v5n3p63 URL: http://dx.doi.org/10.5539/ijel.v5n3p63

\begin{abstract}
The acquisition of lexical collocations, in general, has been regarded as a stumbling block for EFL learners; it is one of the most difficult areas as it is often perceived as being arbitrary. This study tests whether fifty Kuwait EFL learners are aware of one type of lexical collocations, namely, binomials (e.g., up and down, salt and pepper, men and women). Specifically, it investigates whether the participants' English proficiency level and the syntactic category of the internal components of binomials play a role in their acquisition. For this purpose, the researchers used an acceptability judgment task to check the participants' awareness of binomials in English. The results revealed that the participants' English proficiency level affected their answers on the test. In particular, the advanced learners performed better than the intermediate learners. However, the difference between the two groups was not enough to differ statistically. Additionally, the statistical analysis shows that the syntactic category of the components of binomials i.e., $\mathrm{N}+\mathrm{N}$ and $\mathrm{V}+\mathrm{V}$ had no influence on the participants' answers. The researchers concluded that Kuwaiti EFL learners have little awareness of English binomials. Their lack of awareness was attributed to several reasons, such as L1 negative transfer, the existence of culture-specific items and lack of exposure to certain items. The study recommended that further research is required in this area.
\end{abstract}

Keywords: Binomials, L1 transfer, lexical collocations, Kuwait EFL learners, acquisition of lexical items

\section{Introduction}

The acquisition of lexical items has started to capture the attention of many researchers recently due to their vital importance in theoretical linguistics in general, and language acquisition in particular (Meara, 2002, p. 393). This importance stems from the role played by the knowledge of lexical items; a knowledge that is viewed as the most prominent means of communication between interlocutors who speak different tongues. As a result of the interaction with various languages, the need to learn the vocabulary (i.e., collocations) pertinent to those languages has intensified drastically. Collocations have been seen as words that are weaved together by cohesive force, yielding an idiomatic meaning in some cases (Halliday \& Hasan, 1976). One type of lexical collocations is referred to as 'binomials'. They are defined as lexical pairs, in which, two words related to same lexical category are joined together in a fixed order by a conjunction i.e., and and or (McCarthy \& O'Dell, 1994, p. 154). Examples of binomials in English are salt and pepper $(\mathrm{N}+\mathrm{N})$, on and off (Prep+Prep), give and take $(\mathrm{V}+\mathrm{V})$, right and wrong (ADJ+ADJ), and good and bad (ADV+ADV).Binomials, as a type of lexical collocations, are important since they make spoken and written language stimulating and interesting (Kane1983). Using collocations may make EFL learners sound more native-like that is, their speech will be less literal and monotone. The mastery of such expressions may enhance the learners' oral and written skills in the target language; thus, their importance. Additionally, it has been observed that binomials play a crucial role in second language (L2) learners' fluency and accuracy, language appropriateness and word knowledge. However, the acquisition of binomials, as a type of lexical collocations, has not received much attention. Thus, this study investigates the extent to which the English proficiency level of fifty Kuwaiti EFL learners plays a role in their performance on the test. Also, it tests whether the syntactic category of the internal components of binomials can affect the participants' answers on the test. The ultimate goal is to examine the extent to which fifty Kuwaiti EFL learners are aware of English binomials.

\section{Literature Review}

Despite the fact that collocations play a major role in language acquisition, very few studies have been conducted to tackle this issue. For instance, based on an extensive study, Hatch and Brown (1995) argued that 
EFL/ESL learners acquire collocations as a block rather than compositional words that can be grouped together to form a chunk. In fact, Schmitt (2000) indicated that L1 learners not only acquire chunks, such as collocations, through exposure to stimuli during their life, but also develop the capacity or the competence to reconstruct these chunks. On the other hand, EFL/ESL learners can develop the ability to acquire these chunks; however, they may not develop the same ability exhibited by first language (L1) learners, namely, reconstructing the chunks and manipulating them (Schmitt, ibid). Nevertheless, it has been argued that EFL learners can achieve a native-like competence of collocations, provided that they have the ability to use them fluently (Ellis, 1997, p. 9). In other words, the continuous use of collocations in every-day speech may stimulate the learners' memory to retain such expressions and to utilise them repeatedly in their appropriate contexts (Ellis, ibid).

In particular, Lewis (2000) indicated that in order for teachers to maximise vocabulary and collections' retention by students, they need to encourage them to pay more attention to the types of chunk they come across in their text-books and reading materials. It has been proposed, however, that this approach may have some shortfalls as it may not be easy for students to notice these types of phrases in a short time. Hence, to overcome this obstacle, it has been suggested that teachers need to allocate more time to discussing and explaining the importance of acquiring collocations repeatedly. This may help steer the students' attention to the advantages that can be gained by mastering the use of collocations in English (Lewis, ibid).

Amongst the researchers who investigated the acquisition of English collocations by Arab EFL learners is Bahumaid (2006). Specifically, he conducted a study to investigate the relative difficulty of translating English collocations into Arabic and vice versa. For Bahumaid (2006), lexical collocations refer to a lexical category that can be placed between idioms and free combinations. The study also explored the type of lexical collocations that can be perceived as difficult by Arab translators, especially those who taught translation at universities and worked as translators. For this purpose, a translation test that contained both English and Arabic collocations was used. The results revealed that the respondents' overall performance on the test was poor. It also showed that the respondents encountered difficulties with certain types of collocations compared to others. The difficulties were most manifest when the participants had to translate collocations that had a figurative meaning. This difficulty was attributed to the fact that the participants' competence in the target language is limited as opposed to their mother tongue. Bahumaid (2006) recommended that a compulsory course on English collocations should be included at Arab institutes and colleges for translation.

In another recent study, Shehata (2008) explored the impact of L1 on the respondents' comprehension and production of English collocations. The study also investigated whether the amount of exposure to English can play a role in the acquisition of collocations by Arab EFL learners. Ninety seven advanced Arab EFL learners participated in the study. The researcher used two types of test, namely, fill-in the-blank and an acceptability judgment task. The former was used to test the respondents' ability to produce collocations, while the latter tested their comprehension of collocations. The results revealed that the amount of exposure did play a role in the respondents' ability to produce and perceive English collocations. In addition, it was found that L1 have influenced the respondents' answers on the two tests. In particular, negative and positive L1 transfer played an essential role in the acquisition of English collocations by Arab EFL learners. For instance, the English collocations that have an equivalent in Arabic were produced easily, which means that positive transfer from L1 had a substantial influence on the respondents' answers on the two tests. Shehata (2008) concluded that students need to be more exposed to English collocations so that they can receive as much input as possible to enhance their retention.

In a similar vein, Yamashita and Jiang (2012) conducted a study to investigate L1 influence on L2 acquisition of English collocations by Japanese ESL users and EFL learners. The study compared the performance of native speakers of English, Japanese ESL users, and Japanese EFL learners on an acceptability judgement task. In the test, Yamashita and Jiang (2012) used lexical collocations which are similar in both L1 and L2, and other collocations that are different in the two languages. The reason for this process was to check whether L1 has an influence on the respondents' answers on the test. The results showed that EFL learners provided faulty answers on lexical collocations which are different in both languages. In addition, it was found that ESL users outperformed their EFL learners counterparts, which means that use and exposure to L2 can play a role in the respondents' mastery of English collocations. However, the respondents' overall performance suggests that even ESL users faced difficulties with those collocations that are different in both languages. The two researchers concluded that when L2 collocations are stored in memory, they are processed independently of L1, which is possibly why EFL learners face difficulties with acquiring lexical collocations in L2. 
Looking at the literature review on the acquisition of lexical collocations by EFL learners in English, one may notice that little attention has been given to the acquisition of binomials by EFL learners in general, and Arab EFL learners in particular. Therefore, it can be suggested that this area requires further exploration. Hence, this study aims to provide answers to the following questions:

1) To what extent does the English proficiency level of fifty Kuwaiti EFL learners influence their acquisition of English binomials?

2) Does the syntactic category of the internal components of binomials play a role in the participants' performance on the test?

The next section provides an overview of the methodology.

\section{Methodology}

\subsection{The Sample}

The sample consisted of fifty students at the Public Authority of Applied Education and Training (PAAET) and College of Basic Education (CBE).Their mean age was 22 years old and they were all native speakers of Kuwaiti Spoken Arabic (KSA). To ensure the validity of the results, the researchers selected the participants randomly. Since the participants' English proficiency level is an independent variable, the researchers selected the participants based on their scores on the English Placement Test (EPT). In particular, those who scored 50-69 on the EPT were considered intermediate, whilst those who scored $70-85$ were considered advanced. Therefore, the fifty participants were divided into two groups: (1) twenty five Intermediate Learners (ILs); and (2) twenty five Advanced Learners (ALs). It has been indicated by Lewis (2000) that participants with low English proficiency would not usually pass a test on English collocations prior to reaching that point where they have a clear sense of L2. Hence, participants with low English proficiency level were not included in this study. It should be noted that the participation in this study was voluntary; the researchers explained the procedure to the participants, and only those who agreed to be involved were included.

\subsection{The Test}

The researchers used an acceptability judgement task to test the participants' awareness of binomials in English. Other researchers such as Shehata (2008) and Yamashita and Jiang (2012) used this task in their studies since it elicits valuable results that can enable the researchers to make putative generalisations and arrive at logical conclusions. Also, an acceptability rather than grammaticality judgement task was used, since using binomials in a reversed order may not be perceived as ungrammatical, rather as unacceptable. The participants were asked to tick the sentences they thought to be acceptable and cross the ones they thought to be unacceptable. Each binomial was used in two sentences; in the first one it was used in the correct order (i.e., salt and pepper), whilst in the second it was used in a reversed order (i.e., pepper and salt). Thus, overall, the test included 40 sentences (see Appendix A). Table 1 below shows the binomials that were used in the current study.

Table 1. $\mathrm{N}+\mathrm{N}$ and $\mathrm{V}+\mathrm{V}$ binomials used in the test

\begin{tabular}{ll}
\hline $\mathbf{N}+\mathbf{N}$ binomials & $\mathbf{V}+\mathbf{V}$ binomials \\
\hline pros and cons & give and take \\
man and wife & toss and turn \\
salt and pepper & win or lose \\
bread and butter & rise and shine \\
tooth and nail & crash and burn \\
facts and figures & hit and run \\
life and death & hide and seek \\
fish and chips & buy and sell \\
flesh and blood & rock and roll \\
soap and water & open and shut \\
\hline
\end{tabular}

These binomials were chosen based on their frequency in the Corpus of Contemporary American English (COCA). For instance, salt and pepper was mentioned 4719 times and hide and seek 125 times. However, it has been observed that $\mathrm{N}+\mathrm{N}$ binomials are more frequent than $\mathrm{V}+\mathrm{V}$, which may suggest that the participants' may encounter more problems with $\mathrm{V}+\mathrm{V}$ binomials on the test. 


\subsection{The Statistical Analysis}

For the purpose of this study, the Statistical Package for the Social Sciences (SPSS) was used to analyze the participants' answers on the test. Specifically, the researchers calculated the means of the participants' answers in both ILs and ALs groups. The reason for using the means was to: (1) determine whether there are differences between the two groups i.e., ILs and ALs regarding their answers on the test; and (2) identify the most problematic type of binomials i.e., $\mathrm{N}+\mathrm{N}$ or $\mathrm{V}+\mathrm{V}$. Furthermore, a t-test was used to check whether there are statistically significant differences between the two groups i.e., ILs and ALs.

\section{Results and Discussion}

As mentioned previously, this study aims to test whether the English proficiency level of fifty Kuwaiti EFL learners plays a role in their acquisition and use of English binomials. It also aims to check whether the syntactic category of the components of binomials affects the participants' answers on the test. An examination of table 2 demonstrates that ALs (42.2\%) performed better than ILs (36.4\%) on the test. Additionally, table 2 shows that the total mean of all answers by both ALs and ILs on both types of binomials was $39.3 \%$. This result shows that Kuwaiti EFL learners have little awareness of binomials in English.

Table 2. Results of (ALs) and (ILs) on the basis of $\mathrm{N}+\mathrm{N}$ and $\mathrm{V}+\mathrm{V}$ binomials

\begin{tabular}{llll}
\hline & Advanced Learners (ALs) & Intermediate Learners (ILs) & Mean of total answers \% \\
\hline $\mathbf{N}+\mathbf{N}$ binomials & $42.8 \%$ & $36.8 \%$ & $39.8 \%$ \\
V+V binomials & $41.6 \%$ & $36 \%$ & $38.8 \%$ \\
Mean of total answers $\%$ & $42.2 \%$ & $36.4 \%$ & $39.3 \%$ \\
\hline
\end{tabular}

Despite the differences in the percentages between ALs and ILs, there is no statistically significant difference between the two groups in terms of using English binomials; the statistical significance (0.209) is higher than $(0.05)$ as shown in table 3. This means that the English proficiency level plays no role in the acquisition of binomials by Kuwait EFL learners.

Table 3. Results of t-test of differences between (ALs) and (ILs)

\begin{tabular}{lllllll}
\hline Proficiency Level & N & M & SD & t & Df & Sig. \\
\hline Advanced Learners (ALs) & 25 & 4.22 & 2.62 & -1.120 & 48 & $0.209^{* *}$ \\
Intermediate Learners (ILs) & 25 & 3.64 & 2.44 & & & \\
\hline
\end{tabular}

**Significance level $>0.05$.

Testing whether the syntactic category of the internal components of binomials plays a role in their comprehension by Kuwaiti EFL learners, it seems that the syntactic category plays no role in the comprehension either. The statistical significance $(0.269)$ is higher than $(0.05)$, which means that there is no statistically significant difference between the results of $\mathrm{N}+\mathrm{N}$ binomials and $\mathrm{V}+\mathrm{V}$ binomials as shown in table 4 .

Table 4. Results of t-test of differences between $\mathrm{N}+\mathrm{N}$ and $\mathrm{V}+\mathrm{V}$ binomials

\begin{tabular}{lllllll}
\hline Syntactic Category & N & M & SD & t & Df & Sig. \\
\hline N+N Binomials & 10 & 3.98 & 2.58 & -2.542 & 18 & $0.269^{* *}$ \\
V+V Binomials & 10 & 3.88 & 2.08 & & & \\
\hline
\end{tabular}

**Significance level $>0.05$.

Table 5 and 6 provide a clear and comprehensive description of the results, showing in detail the percentages of correct answers on each item on the test i.e., $\mathrm{N}+\mathrm{N}$ and $\mathrm{V}+\mathrm{V}$ binomials. For the readers' convenience, the researchers divided the results into two tables as follows; table 5 shows the participants' results on $\mathrm{N}+\mathrm{N}$ binomials, whereas table 6shows the participants' results on $\mathrm{V}+\mathrm{V}$ binomials. 
Table 5. Percentage of correct answers on $\mathrm{N}+\mathrm{N}$ binomials

\begin{tabular}{llll}
\hline \multirow{2}{*}{ N+N binomials } & \multicolumn{2}{c}{ Percentage of correct answers \% } & \\
\cline { 2 - 3 } pros and cons & Advanced Learners (ALs) & Intermediate Learners (ILs) & Mean of total answers \% \\
\hline man and wife & $64 \%$ & $56 \%$ & $60 \%$ \\
salt and pepper & $32 \%$ & $24 \%$ & $28 \%$ \\
bread and butter & $36 \%$ & $32 \%$ & $34 \%$ \\
tooth and nail & $24 \%$ & $20 \%$ & $22 \%$ \\
facts and figures & $52 \%$ & $48 \%$ & $50 \%$ \\
life and death & $60 \%$ & $52 \%$ & $56 \%$ \\
fish and chips & $64 \%$ & $56 \%$ & $60 \%$ \\
flesh and blood & $20 \%$ & $20 \%$ & $20 \%$ \\
soap and water & $60 \%$ & $48 \%$ & $54 \%$ \\
Mean of total answers $\%$ & $42.8 \%$ & $12 \%$ & $14 \%$ \\
\hline
\end{tabular}

Table 6. Percentage of correct answers on V+V binomials

\begin{tabular}{llll}
\hline \multirow{2}{*}{ V+V binomials } & \multicolumn{2}{c}{ Percentage of correct answers \% } & Mean of total answers \% \\
\cline { 2 - 3 } give and take & Advanced Learners (ALs) & Intermediate Learners (ILs) & \\
\cline { 1 - 2 } toss and turn & $20 \%$ & $16 \%$ & $18 \%$ \\
win or lose & $32 \%$ & $24 \%$ & $28 \%$ \\
rise and shine & $60 \%$ & $52 \%$ & $56 \%$ \\
crash and burn & $32 \%$ & $24 \%$ & $28 \%$ \\
hit and run & $40 \%$ & $40 \%$ & $40 \%$ \\
hide and seek & $60 \%$ & $52 \%$ & $56 \%$ \\
buy and sell & $64 \%$ & $60 \%$ & $62 \%$ \\
rock and roll & $28 \%$ & $24 \%$ & $26 \%$ \\
open and shut & $48 \%$ & $44 \%$ & $46 \%$ \\
Mean of total answers\% & $41.6 \%$ & $24 \%$ & $28 \%$ \\
\hline
\end{tabular}

Regarding the performance of ALs and ILs in relation to the items pros and cons $(60 \%)$, facts and figures (56\%) and hide and seek (62\%), it seems that these items have high percentages in comparison with soap and water (14\%), fish and chips (20\%) and open and shut (28\%). The high percentages of these items may be due to their high frequency in contemporary speech as shown in the COCA; they occur 741, 221 and 125 times respectively. However, one may argue that the frequency is not always an indication of the learners' awareness of certain items in a language. Among these items, give and take (285 times) and soap and water (261 times) occur more than facts and figures (221 times) and hide and seek (125 times) in the COCA. Here, the researchers may argue that exposure to the items, rather than their frequency, is the main reason behind their correct use by the participants. This is explained in detail below:

1) The participants scored higher on both facts and figures (56\%) and pros and cons (60\%) compared to the other items. This may be due to their frequent occurrence in the IELTS exam. That is, task one of the writing exam requires the students to evaluate the pros and cons of a certain issue or provide an explanation of the facts and figures provided on the test. A quick look at the online samples of IELTS exam demonstrates that all materials usually use these items to explain how to do the writing task. Also, many samples of the test, which are suggested by academic websites, are studied by EFL learners as a guide to pass the exam. Most Kuwaiti EFL learners are encouraged to do this test before enrolling at universities. Also, many Kuwaiti EFL learners take the IELTS test for potential BA, MA or PhD scholarships in the UK, the USA, Canada or Australia.

2) With regard to hide and seek (62\%), the researchers note that this item is usually used at schools in Kuwait. Hide and seek is the preferred game which the students usually play at school. EFL teachers, in Kuwait, use this item many times compared to the other items. As a result, it can be argued that the participants have done well on this item since they have been exposed to it more than enough during their time at school.

Moving to the items on which the participants scored low, such as give and take (18\%), soap and water (14\%) and buy and sell (26\%), it seems that L1 interference plays a role in the participants' erroneous answers on the 
test (cf. Shehata 2008):
(1) rafad yaaxið
w yaCtii
maSi
refused.he take.he
and give.he
with me
'He refused to take and give'
$\begin{array}{lll}\text { (2) Pistaxdim 1-maa } & \text { w } \underline{\text { s-saabuun }} \\ \text { use.you the-water } & \text { and the-soap }\end{array}$
'use the water and soap'
$\begin{array}{llllll}\text { (3) laazim } & \text { te } \text { raf } & \text { kiif tbiiৎ } & \text { w tiftiri } & \text { fi } & \text { s-suuq } \\ \text { should } & \text { know.you } & \text { how sell.you } & \text { and buy.you } & \text { in } & \text { the-market }\end{array}$
'you should know how to sell and buy at the market'

Examining examples (1-3), it seems that the participants may have literally translated the binomials from Arabic into English. In Arabic, take and give, water and soap and sell and buy are used instead of their English counterparts give and take, soap and water and sell and buy. The literal translation from Arabic into English causes the misuse of these binomials in English. Hence, this may explain the participants' low scores on those items on the test.

On the other hand, positive transfer from Arabic may have contributed to the participants' correct answers on the test regarding some items. For instance, flesh and blood (54\%), tooth and nail (50\%), life and death (60\%), hit and run (56\%) and win or lose (56\%) exist in Arabic in the same order. Thus, one may argue that positive transfer from Arabic may have contributed to the participants' correct answers on the test. The Arabic counterparts of the above binomials can be seen in examples (4-8):
(4) haaða lahmak
w dammak
this flesh.yours and blood.yours
'this is your own flesh and blood'
(5) daafaৎ Canni bi-Pasnaanuh w Pag faaruh
defended.he me with-teeth.his and nails.his

'he defended me with his teeth and nails'
(6) haaðihi mas?alit hayaah Paw mo:t this matter life or death

'it's a matter of life or death'
(7) mumkin tfuuz Paw texsar
possible win.you or lose.you in this the-game

'you may win or lose in this game'
(8) 1-Pirhaabiyyiin dayman yudrubuun $w$ yuhrubuun
the-terrorists always hit and run

'terrorists always hit and run'

It can be argued that positive transfer from L1 plays a positive role in the participants' correct answers on the test; hence, in the acquisition of English binomials in general. Even though the percentages of flesh and blood (54\%), tooth and nail (50\%), life and death (60\%), hit and run (56\%) and win or lose (56\%) are not quite high, their percentages are higher than other items e.g. buy and sell (26\%) and open and shut (28\%). Literal translation of those five items in Arabic matches their English counterparts. In addition, the use of the previous items (4-8) in Arabic is almost the same as in English, which may have helped the participants tick the correct answer on the test.

Finally, one factor which may have contributed to the participants' wrong answers on the test is the fact that some binomials are culture-specific. Both fish and chips(20\%) and bread and butter (22\%)are items that are used extensively in the UK, especially fish and chips.Fish and chips is a hot English dish, consisting of fish, commonly Atlantic cod or haddock, and fried chips. It is a common take-away food and it is mostly popular in the UK. Therefore, the participants may have not been aware of this item; hence, they chose chips and fish (80\%) 
instead. The same argument applies to bread and butter 'something that provides your main income'. In Arabic, there is no equivalent to this item, which may have made it difficult for Kuwaiti EFL learners to predict that the correct use is bread and butter not butter and bread.

\section{Conclusion and Recommendations}

This study examined the extent to which the English proficiency level of Kuwaiti EFL learners and the syntactic category of the internal components of binomials play a role in their awareness of binomials in English. The results revealed that Kuwaiti EFL learners have little awareness of English binomials. Additionally, the results showed that the participants' English proficiency level played no role in their answers on the test. The difference between the two groups was not enough to differ statistically. Furthermore, the statistical analysis showed that whether the syntactic category of the internal components of binomials is $\mathrm{N}+\mathrm{N}$ or $\mathrm{V}+\mathrm{V}$, the participants' answers were not affected. However, some differences in the participants' answers were detected concerning certain items; these differences were attributed to several reasons. The most significant reason is L1 interference i.e., positive vs. negative transfer. If the item has an equivalent in Arabic and in the same order as in English, the participants scored higher. However, if the order of the binomials in Arabic is reversed, the participants scored lower. The second reason is the exposure to the item e.g. IELTS preparation or school games such as hide and seek. The last reason is associated with the universality of the item and its use. If the binomial is culture-specific such as fish and chips, the participants tend to provide the wrong answer. The participants were not aware of the traditional English meal fish and chips. This study suggests that curriculum designers in Kuwait need to incorporate and highlight the importance of English binomials through well-structured activities and tasks. More studies need to be conducted on the lack of awareness of binomials by Kuwaiti EFL learners in different languages, such as French, and the methods that should be used to acquaint them with such expressions. Teachers need to highlight binomials during reading activities, and draw students' attention to the fact that binomials should not be reversed due to translation of the Arabic counterpart if it existed.

\section{References}

Bahumaid, S. (2006). Collocation in English-Arabic translation. Bable, 52, 133-152. http://dx.doi.org/10.1075/babel.52.2.03bah

Ellis, N. C. (1997). Vocabulary acquisition: word structure, collocation, word-class, and meaning. In N. Schmitt \& M. McCarthy (Eds.), Vocabulary: Description, Acquisition and Pedagogy (pp. 122-139). Cambridge: Cambridge University Press.

Halliday, M. A. K., \& Hasan, R. (1976).Cohesion in English. London: Longman.

Hatch, E., \& Brown, C. (1995). Vocabulary, Semantics, and Language Education. Cambridge: Cambridge University Press.

Kane, T. (1983). The Oxford Guide to Writing: A Rhetoric and Handbook for College Students. Oxford: Oxford University Press.

Lewis, M. (2000). Language in the lexical approach. In M. Lewis (Ed.), Teaching Collocation: Further Developments in the Lexical Approach (pp. 126-154). Language Teaching Publications.

McCarthy, M., \& O’Dell, F. (1994). English Vocabulary in Use. Cambridge: Cambridge University Press.

Meare, P. (2002). The rediscovery of vocabulary. Second Language Research, 18, 393-408. http://dx.doi.org/10.1191/0267658302sr211xx

Schmitt, N. (2000). Vocabulary in Language Teaching. Cambridge: Cambridge University Press.

Shehata, A. (2008). L1 Influence on the Reception and Production of Collocations by Advanced ESL/EFL Arabic Learners of English. MA thesis, Ohio University.

Yamashita, J., \& Jiang, N. (2012). L1 influence on the acquisition of L2 collocations: Japanese ESL users and EFL learners acquiring English collocations. TESOL Quarterly, 44(4), 647-668. http://dx.doi.org/10.5054/tq.2010.235998 


\section{Appendix A}

\section{Acceptability Judgment Task}

Read the following sentences. Put a tick $(\checkmark)$ next to any sentence you think is acceptable and a cross $(X)$ next to any sentence you think is unacceptable. Your first decision is the one we want. Please do not change your answers.

\begin{tabular}{|c|c|c|}
\hline 1. & We need to look at the pros and cons of each system. & $\checkmark$ \\
\hline 2. & This kind of take and give will help you save your marriage. & $x$ \\
\hline 3. & The judge pronounced them man and wife. & $\checkmark$ \\
\hline 4. & $10 \%$ percent of run and hit cases are never resolved. & $x$ \\
\hline 5. & The cook seasoned the pizza with salt and pepper. & $\checkmark$ \\
\hline 6. & Some people do not like pepper and salt on their pasta. & $x$ \\
\hline 7. & "Rise and shine sweetie", said my mother in the morning. & $\checkmark$ \\
\hline 8. & It does not matter whether you lose or win, it is how you play the game. & $x$ \\
\hline 9. & Ministers have been fighting tooth and nail over this issue. & $\checkmark$ \\
\hline 10. & I hope this band will roll and rock here for several years. & $x$ \\
\hline 11. & There are so many cons and pros of this proposal. & $x$ \\
\hline 12. & Let me give you just a few facts and figures. & $\checkmark$ \\
\hline 13. & This is definitely not a shut-and-open case. & $x$ \\
\hline 14. & Tourism is the island's bread and butter. & $\checkmark$ \\
\hline 15. & The two countries fought nail and tooth over this land. & $x$ \\
\hline 16. & You should wash your hands with water and soap before eating. & $x$ \\
\hline 17. & I was tossing and turning all night. & $\checkmark$ \\
\hline 18. & A buy-and-sell agreement will protect the business from collapse if a partner dies. & $\checkmark$ \\
\hline 19. & Chips and fish is one of the most popular dishes in the UK. & $x$ \\
\hline 20. & The police is investigating a fatal hit and run accident. & $\checkmark$ \\
\hline 21. & Working in an insurance company is my butter and bread. & $x$ \\
\hline 22. & The police listened to her call closely since she said that it was a death and life situation. & $x$ \\
\hline 23. & Every wife and man should take care of their children. & $x$ \\
\hline 24. & She used to play hide and seek when she was a child. & $\checkmark$ \\
\hline 25. & They said that the secret of a happy marriage was a little bit of give and take. & $\checkmark$ \\
\hline 26. & I always turn and toss when I am sleeping, especially after drinking coffee. & $x$ \\
\hline 27. & The company burned and crashed after less than a year. & $x$ \\
\hline 28. & They now realise that their hero is, after all, only flesh and blood. & $\checkmark$ \\
\hline 29. & Our lawyerthinks that we have an open-and-shut case. & $\checkmark$ \\
\hline 30. & It is very difficult to remember all the figures and facts related to this proposal. & $x$ \\
\hline 31. & This is our opportunity to shine and rise and be the country that leads the way. & $x$ \\
\hline 32. & This paint can be cleaned with a little soap and water. & $\checkmark$ \\
\hline 33. & The peace process is a matter of life and death in some regions. & $\checkmark$ \\
\hline 34. & Successful companies can sell-and-buy their products all year long. & $x$ \\
\hline 35. & Whether you win or lose, you must be proud that you got this far. & $\checkmark$ \\
\hline 36. & I was playing seek and hide with my brother and I got lost in the woods. & $x$ \\
\hline 37. & If you go on with this thing, you'll crashandburn. & $\checkmark$ \\
\hline 38. & You should try fish and chips when you go to England. & $\checkmark$ \\
\hline 39. & The Internet in Asia is ready to rock and roll. & $\checkmark$ \\
\hline 40. & We cannot worship our leaders, they are only blood and flesh. & $x$ \\
\hline
\end{tabular}




\section{Appendix B}

\section{Arabic Sounds}

\begin{tabular}{|c|c|c|}
\hline Arabic consonants/vowels & Symbols & Description \\
\hline 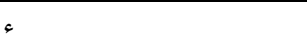 & $?$ & voiceless glottal stop \\
\hline ب & $\mathrm{b}$ & voiced bilabial stop \\
\hline$ت$ & $\mathrm{t}$ & voiceless dento-alveolar stop \\
\hline$ث$ & $\theta$ & voiceless inter-dental fricative \\
\hline ج & $\mathrm{j}$ & voiced post-alveolar affricate \\
\hline$\tau$ & $\underline{\mathrm{h}}$ & voiceless pharyngeal fricative \\
\hline$\dot{\tau}$ & $\mathrm{x}$ & voiceless uvular fricative \\
\hline د & $\mathrm{d}$ & voiced dento-alveolar stop \\
\hline ذ & ə & voiced alveolar fricative \\
\hline Ј & $\mathrm{r}$ & voiced alveo-palatal trill \\
\hline j & $\mathrm{z}$ & voiced alveolar fricative \\
\hline س & $\mathrm{s}$ & voiceless alveolar fricative \\
\hline 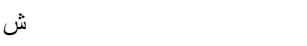 & $\int$ & voiceless alveo-palatal fricative \\
\hline ص & $\underline{\mathrm{s}}$ & voiceless alveolar emphatic fricative \\
\hline 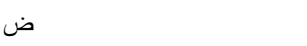 & $\underline{\mathrm{d}}$ & voiced alveolar emphatic stop \\
\hline b & $\underline{t}$ & voiceless dento-alveolar emphatic stop \\
\hline ظ & $\underline{\partial}$ & voiced alveolar emphatic fricative \\
\hline$\varepsilon$ & ৎ & voiced pharyngeal fricative \\
\hline$\dot{\varepsilon}$ & $\gamma$ & voiced uvular fricative \\
\hline ف & f & voiceless labio-dental fricative \\
\hline ق & $\mathrm{q} / \mathrm{g}($ Note 1$)$ & voiceless/voiced uvular stop \\
\hline ك & $\mathrm{k}$ & voiceless velar stop \\
\hline J & 1 & voiced alveolar lateral \\
\hline r & $\mathrm{m}$ & voiced bilabial nasal \\
\hline ن & $\mathrm{n}$ & voiced alveolar nasal \\
\hline 。 & $\mathrm{h}$ & voiceless glottal fricative \\
\hline و & $\mathrm{w}$ & voiced labio-velar glide \\
\hline ي & $\mathrm{y}$ & voiced palatal glide \\
\hline 「l & $\mathrm{a}$ & low short central unrounded \\
\hline li & $\mathrm{u}$ & high short back rounded \\
\hline 1.1 & $\mathrm{i}$ & high short front unrounded \\
\hline i & aa & low long central unrounded \\
\hline وو & uu & high long back rounded \\
\hline يبي & ii & high long front unrounded \\
\hline 9 & o: & mid long back rounded \\
\hline او & aw & low short front unrounded + labio-velar glide \\
\hline أي & ay & low short front unrounded + palatal glide \\
\hline يبي & ee & mid long front unrounded \\
\hline
\end{tabular}

\section{Note}

Note 1 . These symbols represent the voiceless and voiced uvular stop.

\section{Copyrights}

Copyright for this article is retained by the author(s), with first publication rights granted to the journal.

This is an open-access article distributed under the terms and conditions of the Creative Commons Attribution license (http://creativecommons.org/licenses/by/3.0/). 